\title{
OBSTACLES OF APPLYING SCIENCE AND MATHEMATICS TEACHERS' OF FUTURE \\ SKILLS IN BASIC EDUCATION SCHOOLS IN THE SULTANATE OF OMAN FROM THE POINT OF VIEW OF TEACHERS AND EDUCATIONAL SUPERVISORS
}

\author{
Humaid Muslem ALSAIDI ${ }^{1}$ \\ Khalid Juma ALSHIDI ${ }^{2}$
}

\section{Istanbul / Türkiye \\ p. 346-364}

Received: $28 / 11 / 2021$

Accepted: $12 / 12 / 2021$

Published: 01/01/2022

This article has been scanned $l$

iThenticat No plagiarism detected

http://dx.doi.org/10.47832/2717-8293.15.26

1 (iD) Dr. The Ministry of Education, Sultanate of Oman, Hm.alsaidi@gmail.com, https://orcid.org/0000-0001-6251-3571

2 iD Researcher, The Ministry of Education, Sultanate of Oman Khalid.Juma9@ moe.om, https://orcid.org/0000-0002-7619$\underline{1718}$ 


\section{معوقات توظيف معلمي العلوم والرياضيات لمهارات المستقبل بمدارس التعليم الأساسي بسلطنة عمان من وجهة نظر المعلمين والمشرفين التربويين}

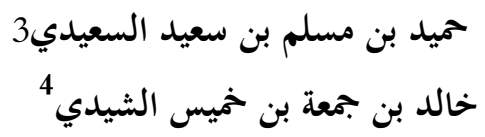

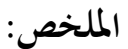

هدفت الدراسة إلى الكشف عن المعوقات التي تحول دون توظيف معلمي العلوم والرياضيات في توظيف مهارات المستقبل في مدارس التعليم الأساسي، ولتحقيق أهداف الدراسة استخدم الباحثان المنهج الوصفي، وذلك بإعداد

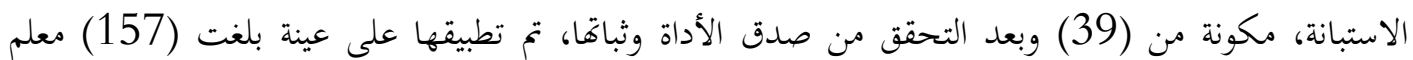
ومعلمة، و(51) مشرفاً ومشرفةً، وقد كشفت نتائج الدراسة أن درجة المعوقات التي يواجهها معلمو العلوم والرياضيات في توظيف مهارات المستقبل بمدارس التعليم الأساسي بسلطنة عمان من وجهة نظر المعلمين والمشرفين

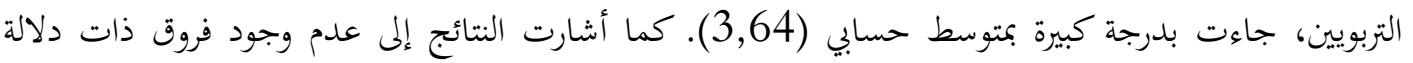
إحصائية عند مستوى دلالة (Q=0,05) بين متوسطات درجة المعوقات تعود إلى متغيرات الوظيفة والجنس، في

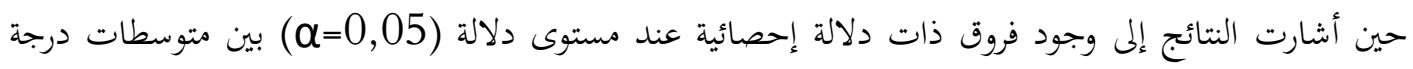

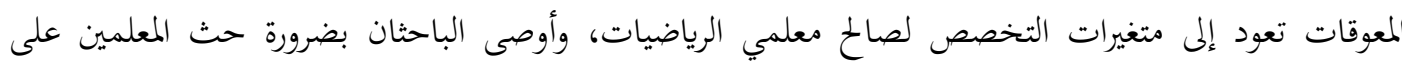
تطبيق الاستراتيجيات التدريسية الحديثة، والأنشطة التقيمية التي تركز على مهارات المستقبل، وضرورة تخفيف الأعباء الإدارية على المعلمين. الكلمات المفتاحية: المعوقات، مهارات المستقبل، معلمي العلوم والرياضات.

يمثل الذكاء الاصطناعي وأنترنت الأشياء أهم مظاهر الثورة الصناعية الرابعة، والتي تمثل مرحلة انتقالية في الحضارة البشرية بما تمثله من انتقال نوعي في أنماط الحياة المختلفة، مما يتطلب أن يمتلك الفرد العديد من المهارات الأساسية التي تتوافق مع متطلبات القرن الحادي والعشرين، لذا أصبح لزاماً على الأنظمة التعليمية العمل على اكساب المخرجات مهارات المستقبل. إذ أنتجت الثورة الصناعية الرابعة فرص عمل كثيرة غير مسبوقة خلافا للثورات السابقة التي اعتمدت العمل اليدوي والآلي المباشر، فقد زادت الثورة الصناعية الرابعة من الطلب النسبي على المهارات بصورة غير متساوية في الوظائف المختلفة، وعلى فرصي الرغم من ذلك فقد خلقت عددا من التحديات المهمة والتي كان من أبرزها المهارات المستقبلية والعمل على تنميتها لدى لمع المتعلمين

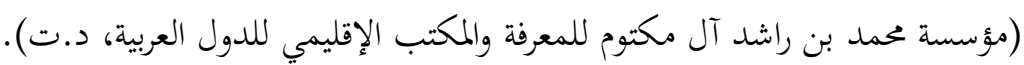

إن إحداث تغيير في مؤسسات التعليم وأنظمتها بجيث تصبح قادرة على استشراف المهارات اللازمة للنجاح في المستقبل

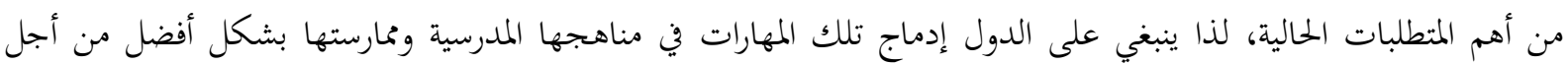
تحسين جودة التعليم، وتعزيز فرص واستمرارية التعلم مدى الحياة وإنشاء روابط وعلاقات أقوى مع الصناعة وسوق العمل واتباع 
طرائق حديثة تستند إلى التكنولوجيا المتطورة، وتعاني بيئة العمل العربية من مشكلات أدت إلى تأخرها في اللحاق بركب الدول المتقدمة (محمد، ومحمد، 2020).

هذا التغيير في الأنظمة التعليمة يتطلب العديد من التغيرات في عناصر العملية التعليمية بدء من المنهاج الدراسي والذي ينبغي أن يتضمن كل ما يتعلق بمهارات المستقبل ومتطلبات القرن الحادي والعشرين إلى جانب الاهتمام بتدريب المعلمين و تأهليهم من أجل تمكينهم من توظيف الأساليب التدريسية الحميثة التي تساعد على اكساب الطلبة هذه المهارات.

لذلك اهتمت سلطنة عمان بوضع إطار وطني للمهارات يرتبط بمجالات التدريس والتدريب، حيث تم اعتماد الإطار الوطني العماني لمهارات المستقبل في العام 2021، وهو إطار شامل، توازن أهدافه بين المتطلبات الوطنية التي تنشدها رؤية عُمان

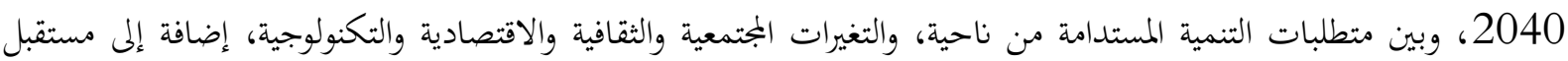

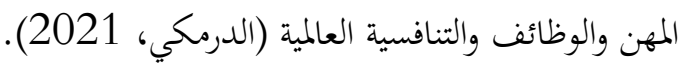
وقد أُعد هذا الإطار الوطني ليكون رُؤية للتربويين والمعنيين بالتعليم في السلطنة تعينهم على تضمين مهارات المستقبل في

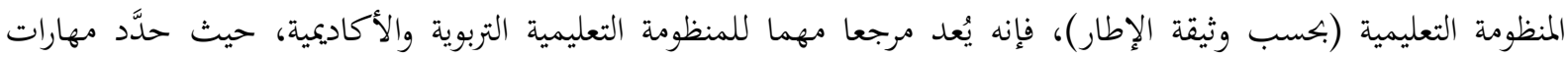
المستقبل في سلطنة عمان وموجهاها، إضافة إلى متطلبات تضمين هذه المهارات في العملية التعليمية، وآليات تطبيقها وفقا للأطر العالمية (بجلس التعليم، 2021).

ومن أجل إدماج مهارات المستقبل في النظام التعليمي، يحتاج المتعلمون إلى بنية متكاملة وشاملة من المهارات حتى يصبحوا من خلالها أكثر فاعلية عند تطبيق مهاراتم في العالم الواقعي، وبما يمكن من تحقيق رؤية سلطنة عمان 2040 والتي يعد فيها

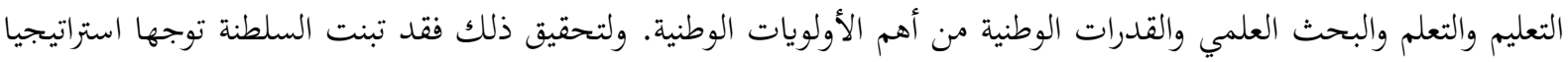
يقوم على تعليم شامل ومستدام وبحث علمي يقود إلى مجتمع المعرفة من خلال التركيز على رفع جودة التعليم وتطوير المناهج

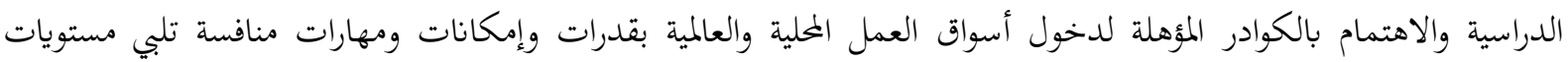

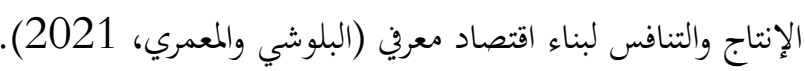
وبما أن المحتوى المعرفي والمهاري في مواد العلوم والرياضيات الذي يقدم في المدارس أمر بالغ الأهمية للنجاح على صعيد

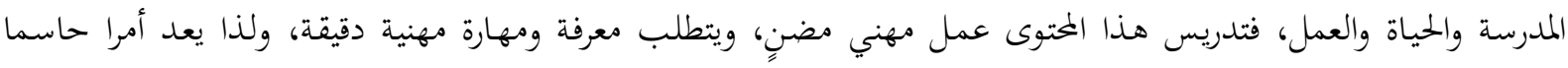
لضمان اكتساب جميع المعلمين المعارف والمهارات اللازمة للتدريس بفعالية. وعلى المعلمين الاستعداد الجيد فيما يتصل بالتعليم والتعلم مستعينين بصور خاصة من الدربة والدراية بموضوع التخصص وبالمهارات المهنية والمعارف المكتسبة عبر الدراسة والممارسة والإلمام بالمختوى وإدراك قضايا المنهج التي يواجها المعلمون في تدريس العلوم والرياضيات (The Economist Intelligence Unit, 2017) وتعد مناهج العلوم والرياضيات من أهم المناهج المرتبطة بتقدم المجتمعات وتطوير المهارات المتنوعة والمرتبطة بالتقدم العلمي،

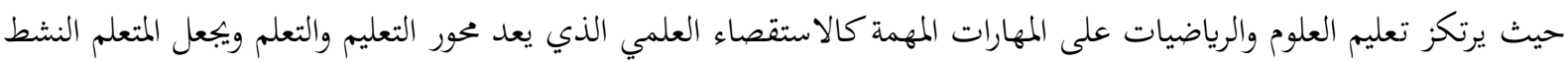

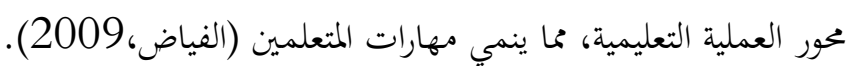

من أجل ذلك كان لا يزال هناك حراك تربوي لتطوير وإصلاح مناهج العلوم على المستوى الدولي والمحلي، وهناك عدد من المعوقات التي تواجه تمكين معلمي العلوم من تدريس المهارات الضرورية واللازمة منها ما يتعلق بالمعلم وتتمثل: في عدم إعداد المعلم

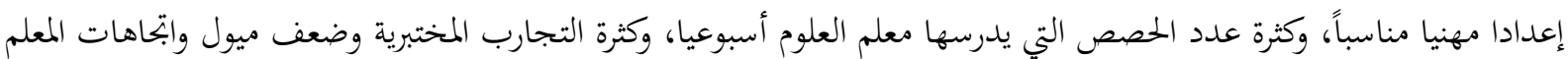
نخو العمل المختبري. ومنها ما يتعلق بالمتعلم المتمثلة في ازدحام الطلبة في الفصول الدراسية، وصعوبة ضبط الطالب في قاعة المختبر 
ومن أجل تنمية مهارات المستقبل سعى عدد من الباحثين إلى تقصي كثير من الجوانب المرتبطة بتنمية تلك المهارات بما

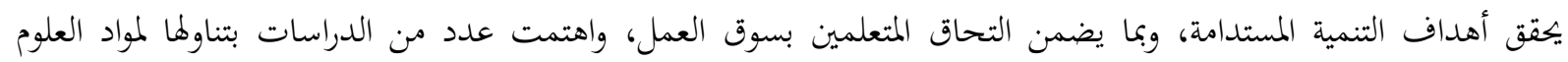
والرياضيات لما لها من قيمة في تنمية مهارات المستقبل. وقد تنوعت تلك الدراسات كما وكيفا، ومنها ما قامت به شهن شبلي (2014) حيث سعت في دراستها إلى تحديد مهارات القرن الحادي والعشرين التي يمكن دمجها في مناهج فئنس العلوم بمرحلة التعليم الأساسي المتوسط بمصر، وتقويم محتوى كتب العلوم في ضوء توافر هذه المهارات. ولتحقيق هذا الهدف اعتمدت الدراسة المنهج الوصفي التحليلي القائم على تحليل محتوى كتب العلوم، وقد أظهرت نتائج الدراسة تدني مستوى تضمين مقررات العلوم لمهارات

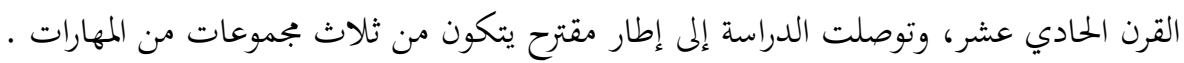
وأجرى البحراوي (2015) دراسة هدفت إلى التعرف على درجة امتلاك الطلاب المعلمين المعايير في ضوء مهارات القرن الحادي والعشرين والمعوقات التي يواجهوها، انتهجت الدراسة المنهج الوصفي التحليلي. واشتملت عينة الدراسة على (179)

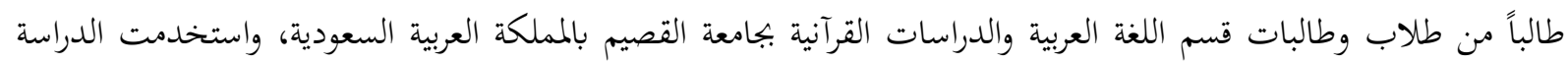

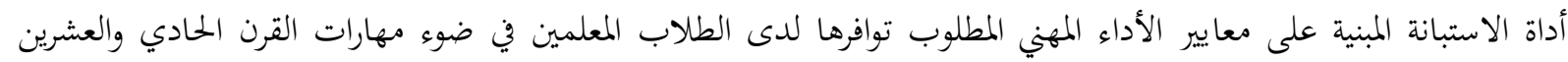

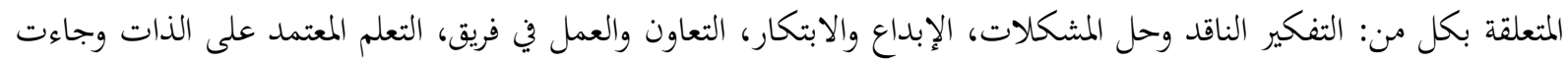
جميعها بدرجة أهمية عالية من وجهة نظر أفراد عينة الدراسة. هدفت دراسة الجهني (2015) إلى التعرف على معوقات تدريس مادة الرياضيات في المرحلة الابتدائية بمحافظة خيبر وسبل تطويرها، وأظهرت نتائج الدراسة وجود عدد من الصعوبات، حيث جاءت في المرتبة الأولى الصعوبات المتعلقة بالمتعلم

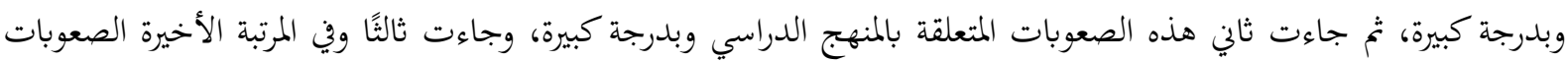

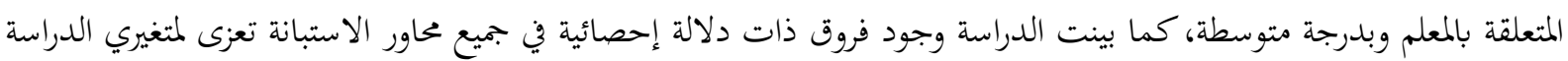

$$
\text { (عدد سنوات الخبرة، صفوف التدريس). }
$$

وأجرت دويكات (2016) دراسة هدفت إلى التعرف على مدى فهم معلمي المرحلة الأساسية الدنيا للمفاهيم الرياضية

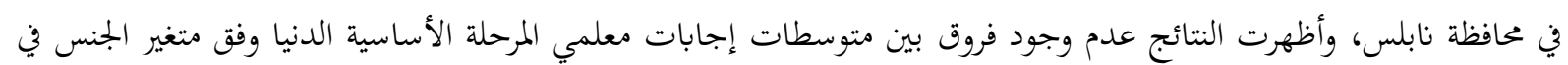

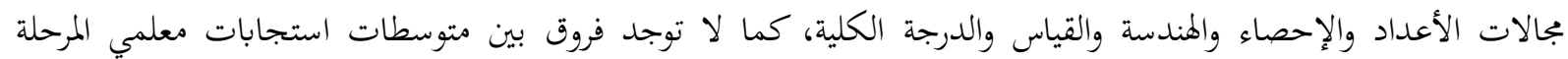
الأساسية وفق متغير عدد سنوات الخبرة في مجال المندسة والقياس، بينما توجد فروق في مجال الأعداد والإحصاء والدرجة الكلية

$$
\text { لصالح المعلمين الأقل خبرة من ه سنوات. }
$$

وأجرى العقالي (2018) دراسة هدفت إلى التعرف على معوقات توظيف تكنولوجيا الواقع الافتراضي في تدريس الرياضيات من وجهة نظر معلمات مادة الرياضيات بجدة في ضوء بعض المتغيرات، استخدمت الدراسة المنهج الوصفي. وكانت

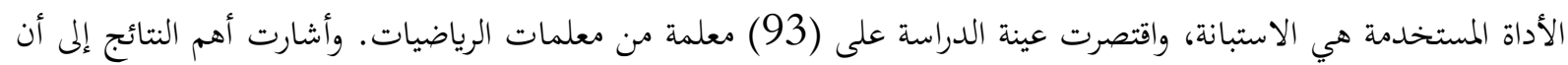

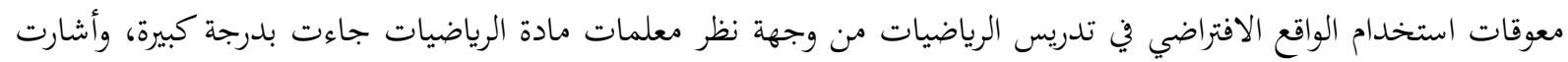

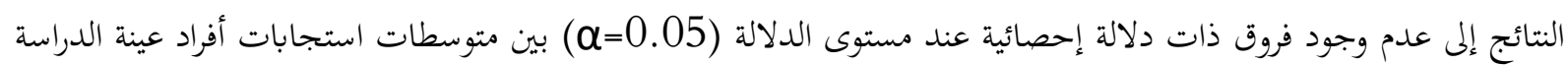
حول معوقات استخدام الواقع الافتراضي في تدريس الرياضيات تُعزى لمتغيري المرحلة التعليمية، وسنوات الخبرة. وهدفت دراسة علامي(2018) إلى التعرُف على درجة تأثير معوقات تدريس المفاهيم الرياضية في الصفوف الأولية من

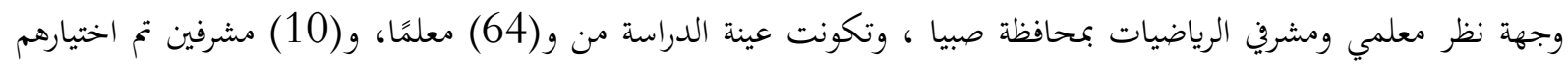

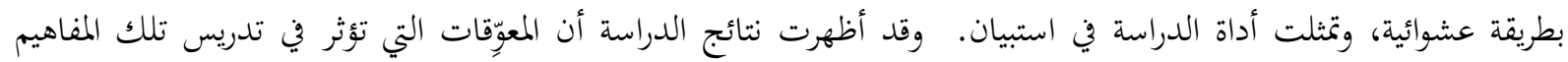


بدرجةٍ عاليةٍ، وجاء في مقدمتها المعوِقات المتعلقة بالبيئة المدرسية بدرجة كبيرة جداً، وجاءت المعوقات المتعلقة بالمعلِّم وبالمتعِلِّم

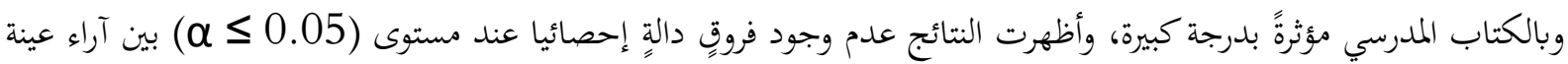
الدراسة تُعزى لمتغيرات: الجنس، وطبيعة العمل، والمؤهل العلمي، وسنوات الخبرة.

وهدفت دراسة الحربي والحسين (2019) إلى التعرف على معوقات تنفيذ الأنشطة التعليمية المضمنة في مقررات العلوم

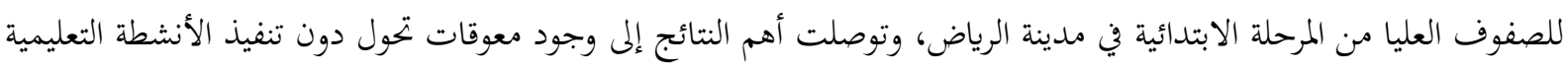

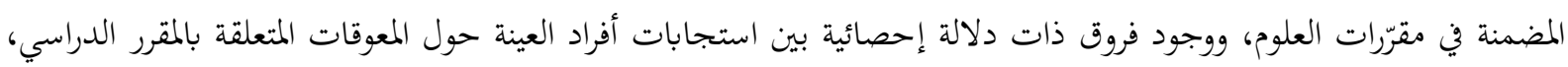

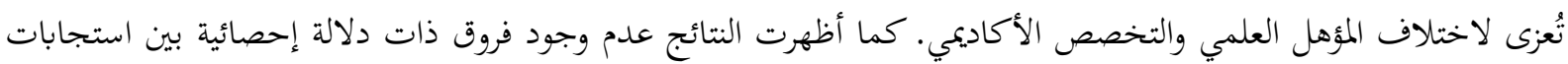
أفراد العينة حول المعوقات المتعلقة بالبيئة المدرسية والطالبات، تعزى لاختلاف المؤهل العلمي والتخصص الأكاديمي، وكذلك حول المول المعوقات المتعلقة بالبيئة المدرسية والمقرر الدراسي والمعلمات، تعزى لعدد سنوات الخبرة لمبنة لأفراد العينة. وهدفت دراسة ملحم (Melhem, 2020) إلى التعرف على مستوى مهارات القرن الحادي والعشرين لدى طلبة قسم

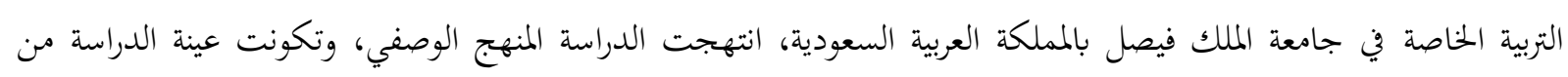
(65) طالبا تم اختيارهم بشكل عشوائي. قام الباحث بتطوير استبيان الدراسة المكون من (80) فقرة حول مهارات القرن الحادي

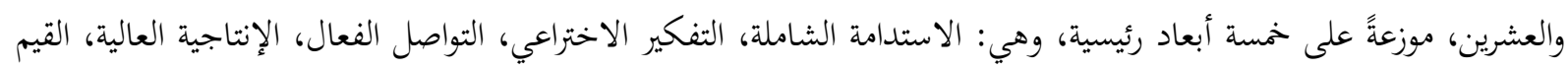
الدينية. وأشارت نتائج الدراسة الى أن مستوى مهارات القرن الحادي والعشرين لدى الطلاب كان ضمن ألمن المستوى المتوسط . وأجرى عليان والمزروعي (2020) دراسة هدفت إلى الكشف عن المعوقات التي تحد من تطبيق منهج STEM المتكامل في تعليم العلوم في سلطنة عمان، والتحقيق في تأثير متغير الجنس في وجود هذه المعوقات. ولتحقيق أهداف الدراس الدراسة تحم

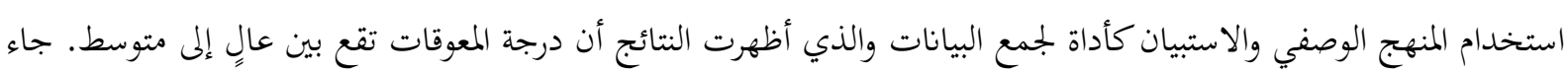
الجزء الثالث (المعوقات المتعلقة بالمحتوى) في المرتبة الأولى بمتوسط (3.51) وبدرجة المانديات عالية، يليه الجزء الثاني (المعوقات المتعلقة ببيئة

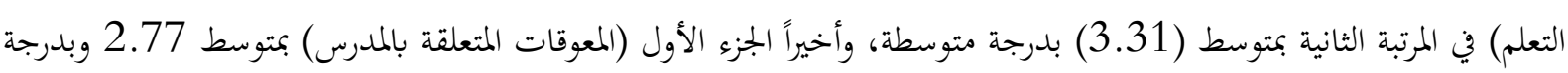

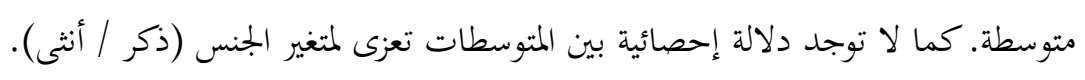
وقد أشارت هذه الدراسات السابقة إلى أهمية توظيف مهارات المستقبل في الموقف التعليمي، كما أكدت على هناك العديد من التحديات التي تواجه المعلمين في توظيف المعلمين للأساليب التدريسية التي تمكنهم من اكساب مهارات المستقبل، كما فئات لاحظ الباحثان قلة الدراسات العمانية التي بحثت في التحديات التي تواجه المعلمين في توظيف مهارات المستقبل لذا تأتي هذه التهات الدراسة للتقصي عن هذه التحديات ومعرفة تأثيرها على أداء المعلمين.

\section{مشكلة الدراسة وأسئلتها:}

أكد مؤتمر القمة العالمي للابتكار في التعليم في قطر ثمة حاجة إلى إجراء بحوث حول المعوقات التي تحول دون تحقيق

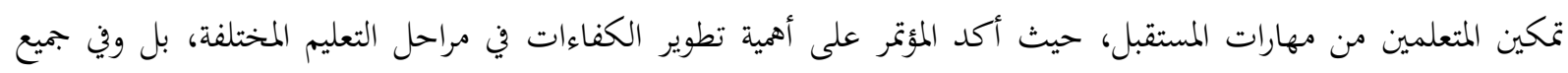

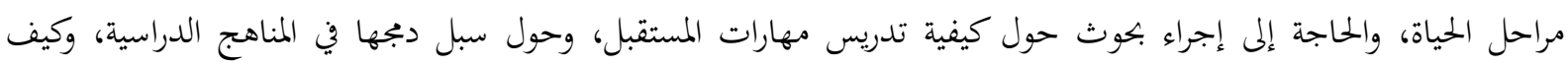

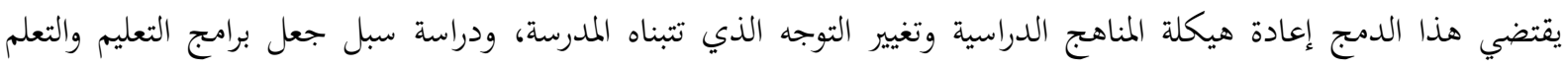

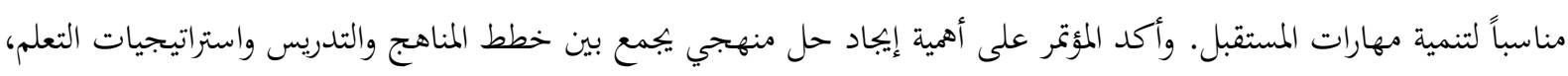

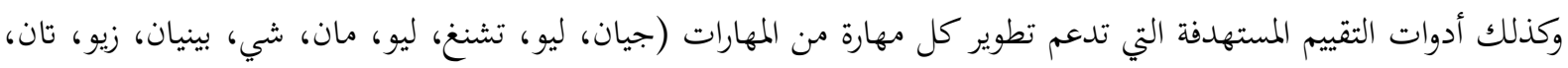
كريس، وخيا، ليو، 2019). 
وأظهر مؤشر جاهزية مهارات المستقبل إلى أن أكثر الدول التي سجلت أعلى نشاط على الانترنت في مجال مهارات

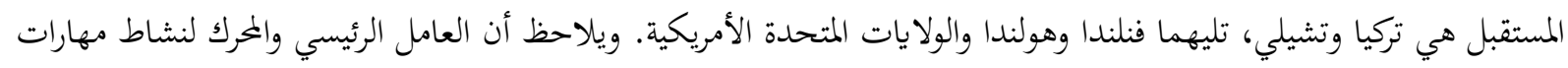

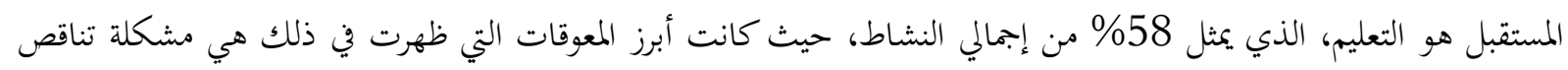

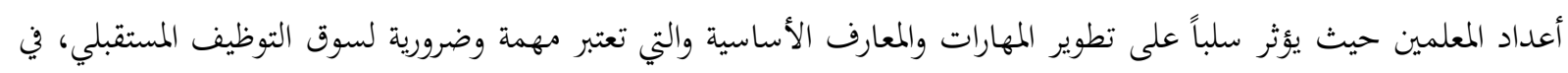

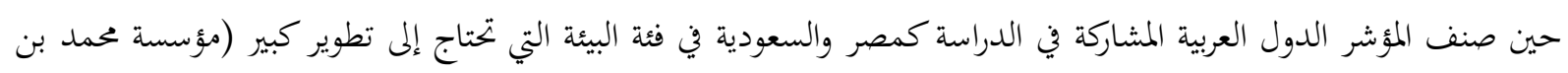
راشد آل مكتوم للمعرفة والمكتب الإقليمي للدول العربية، د.ت).

وأوصت دراسة عبد العال (2018)، باسم وخضير (2020) بأن يكون تنمية مهارات القرن الحادي والعشرين من الأهداف الأساسية لبرامج إعداد المعلمين خصوصا في مواد العلوم والرياضيات، وبالتركيز على إكساب الطلبة مهارات القرن

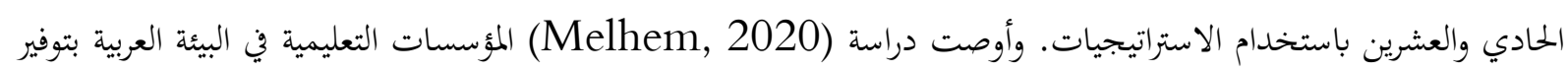
وتعزيز اكتساب مهارات القرن الحادي والعشرين لجميع المتعلمين لتمكينهم من البقاء بقوة في سوق العمل من خلال إعادة العادئ النظر في البرامج والمقررات الجامعية لتتوافق مع متطلبات ومهارات العصر الحالي.

ونبعت هذه الدراسة أيضاً من شعور الباحثان بوجود معوقات يواجها معلمي مادني العلوم والرياضيات في توظيف

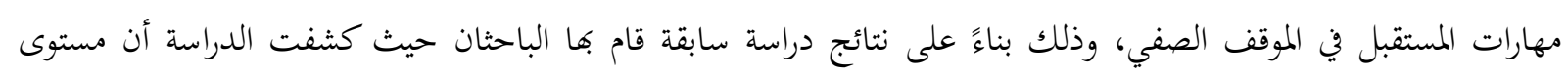

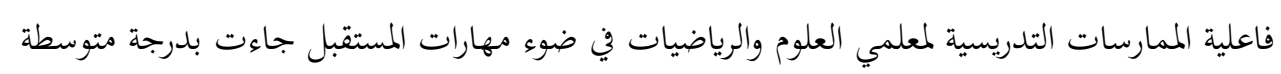
(الشيدي، السعيدي، 2021)، وهذا يتطلب القيام بدراسة علمية للكشف عن المعوقات التي تضعف من توظيف معلمي مادتي العلوم والرياضيات لمهارات المستقبل في الموقف الصفي، وهو ما تمدف الدراسة الحالية إلى تحقيقه.

\section{وتتلخص مشكلة الدراسة في الإجابة عن الأسئلة الآتية:}

1. ما درجة المعوقات التي يواجها معلمو العلوم والرياضيات في توظيف مهارات المستقبل بمدارس التعليم الأساسي بسلطنة عمان من وجهة نظر المعلمين والمشرفين التربويين؟ 2. هل توجد فروق ذات دلالة إحصائية في درجة المعوقات التي يواجها معلمو العلوم والرياضيات في توظيف مهارات المستقبل

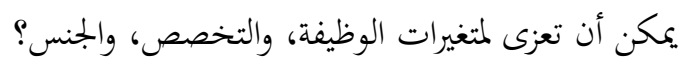

\section{أهداف الدراسة:}

تسعى هذه الدراسة إلى تحقيق الأهداف التالية:

1. تحديد درجة المعوقات التي تحول دون توظيف معلمي العلوم والرياضيات في توظيف مهارات المستقبل في مدارس التعليم الأساسي.

2. الكشف عن أثر متغيرات الوظيفة والجنس والتخصص في تقديرات معلمي العلوم والرياضيات لدرجة المعوقات التي تحول دون توظيفهم مهارات المستقبل في مدارس التعليم الأساسي. 
تكتسب الدراسة أهميتها من المناهج المطورة في العلوم والرياضيات والتي سعت وزارة التربية والتعليم العمانية لربطها بمهارات

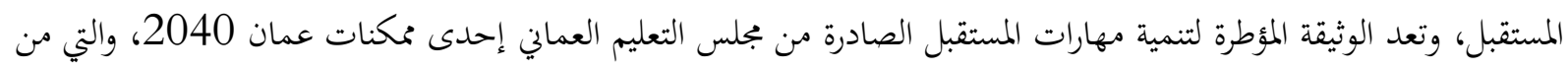

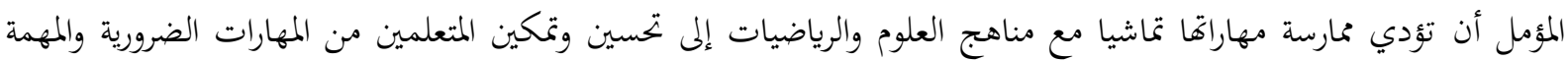

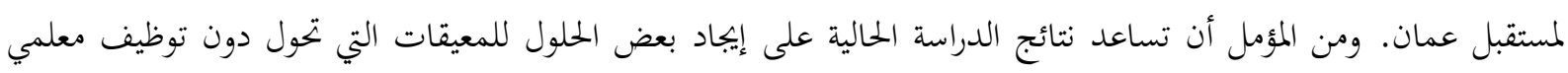

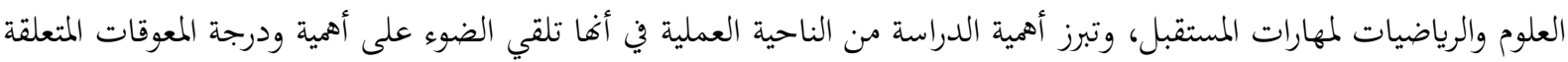
بالمنهج، طرائق التدريس الحديثة، المعلم، والمتعلمين، والتقويم التربوي.

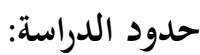

الحدود الموضوعية: اقتصرت الدراسة على تحديد درجة معوقات توظيف مهارات المستقبل في مادتي العلوم الرياضيات. الحدود البشرية: اقتصرت الدراسة على معلمي العلوم والرياضيات والمشرفين التربويين بمرحلة التعليم الأساسي للصفوف بمرحلة التعليم الأساسي.(12-5 (5)

الحدود المكانية: اقتصرت على المدارس الحكومية بمرحلة التعليم الأساسي للصفوف بمرحلة التعليم الأساسي (5-12) في محافظات: مسقط، شمال الباطنة، والبريمي، والداخلية. الحدود الزمانية: أجريت الدراسة في العام الدراسي (2021/ 2022).

مصطلحات الدراسة:

هالمعوقات: أوضاع صعبة يكتنفها شيء من الغموض يحول دون تحقيق الأهداف المرجوة بكفاءة وفاعلية (أبو عابد، 2005).

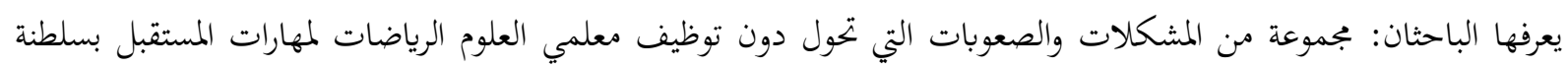
عمان. وهي موزعة على خمسة بحالات هي: المعوقات المتعلقة بمنهج العلوم والرياضات، والمعوقات المتعلقة بطرائق تدريس مهارات المستقبل.والمعوقات التي تتعلق بالمعلم، والمعوقات التي تتعلق بالمتعلم، والمعوقات التي تتعلق بقياس مهارات المستقبل وتقويمها، ومقاسة بمقياس خماسي (كبيرة جداً، كبيرة، متوسطة، قليلة، قليلة جداً). مهارات المستقبل: مجموعة من المهارات الضرورية لضمان استعداد المتعلمين للحياة والعمل وتتضمن الاستخدام الأمثل

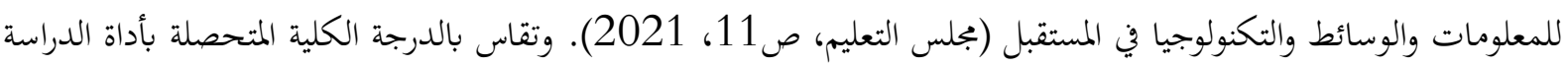
في ضوء مقياس ليكرت الخماسي. ه معوقات مهارات المستقبل: يعرفها الباحثان: هي مجموعة من المشكلات أو الصعوبات التي تحول دون توظيف معلمي العلوم والرياضيات لمهارات المستقبل بسلطنة عمان. وهي ترتبط بخمسة مجالات من المعوقات (المنهج، طرائق التدريس الحديثة، المعلم،

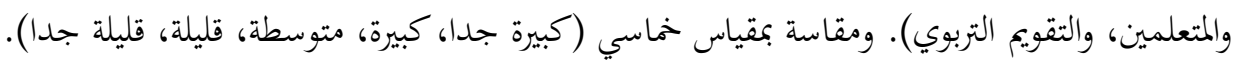
مشرفو العلوم والرياضيات: هم مشرفو العلوم والرياضيات، تخصُصي العلوم والرياضيات، العاملون في المحافظات التعليمية 


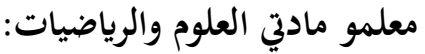

هم معلمو العلوم والرياضيات، العاملون في مدارس الحلقة الثانية من التعليم الأساسي (5-12)، المحافظات التعليمية بسلطنة

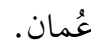

الطريقة والإجراءات مجتمع الدراسة

أ) المعلمون: تألف مجتمع الدراسة من جميع معلمي مادتي العلوم والرياضيات العاملين في مدارس التعليم الأساسي الحلقة الثانية،

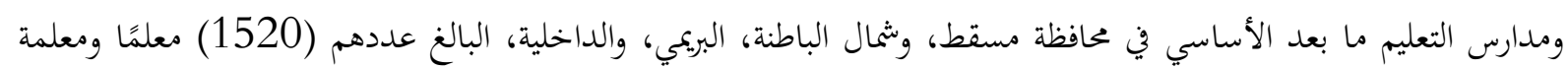

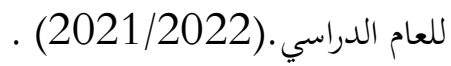

ب) المثرفين التربوين: تألف مجتمع الدراسة من جميع المشرفين التربويين لمادتي العلوم والرياضيات المدارس العاملين في مدارس التعليم الأساسي الحلقة الثانية، ومدارس التعليم ما بعد الأساسي، في محافظة مسقط، وشثمال الباطنة، البريمي، والداخلية البالغ

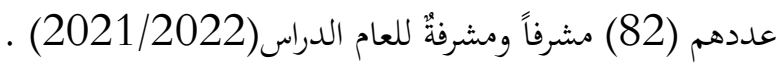

عينة الدراسة (المعلمين): ( تكونت عينة الدراسة من (157) معلمًا ومعلمة، وتم اختيارهم بالطريقة العشوائية البسيطة، وهي الطريقة المناسبة نظرًا

لحجم المجتمع، ويوضح جدول (1) متغيرات الدراسة.

$$
\text { عينة الدراسة (المشرفين): }
$$

وتكونت عينة الدراسة من (51) مشرفاً ومشرفة، وتم اختيارهم بالطريقة العشوائية البسيطة، وهي الطريقة المناسبة نظراً

لحجم المجتمع، ويوضح جدول (1) متغيرات الدراسة. جدول (1) توزيع أفراد عينة الدراسة حسب متغير الجنس للعام الدراسي 2021/2020

\begin{tabular}{|c|c|c|c|}
\hline النسبة المئوية & العدد & \multicolumn{2}{|c|}{ متغيرات الدراسة } \\
\hline $24.5 \%$ & 51 & مشرف تربوي & \multirow[t]{2}{*}{ الوظيفة } \\
\hline $75.5 \%$ & 157 & معلم & \\
\hline $54.8 \%$ & 114 & ذكر & \multirow[t]{2}{*}{ الجنس } \\
\hline $45.2 \%$ & 94 & أنثى & \\
\hline $100 \%$ & 208 & \multicolumn{2}{|c|}{ المجموع } \\
\hline
\end{tabular}

منهج الدراسة:

اعتمد الباحثان في الدراسة المنهج الوصفي، والذي يعتبر مناسباً لهذا النوع من الدراسات، وذلك عن طريق وصف الظاهرة من خلال جمع البيانات الميدانية حولها بواسطة أداة الاستبانة. 
أداة الدراسة (الاستبانة):

لتحقيق أهداف الدراسة قام الباحثان بإعداد استبانة، حيث تكونت أداة الدراسة في صورةا النهائية من (39) عبارة،

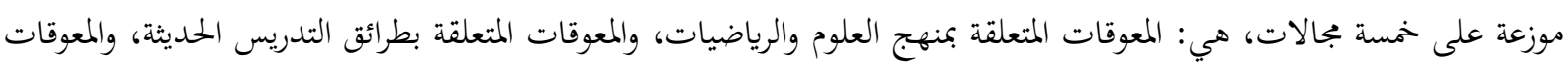
المتعلقة بالمعلم، والمعوقات المتعلقة بالمتعلمين، والمعوقات المتعلقة بالتقويم التربوي.

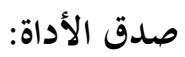

تَّ قياس صدق أداة الدراسة من خلال التحقق من الصدق الظاهري وذلك بعرضها على مجموعة من المحكمين المتخصصين في مجال المناهج وطرق التدريس، والمتخصصين في مهارات المستقبل ثم إجراء التعديلات المقترحة.

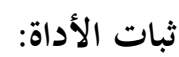

تم التأكد من ثبات الأداة من خلال تطبيقها على عينة تجريبية مكونة من (10) مشرف ومشرفة، (10) معلم ومعلمة،

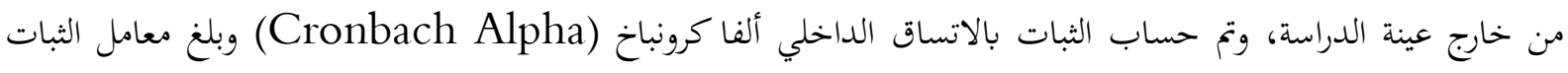
الكلي للأداة (0,869)، بما يفيد ثبات الأداة، وقابليتها للتطبيق من أجل تحقيق أهدات أهداف الدراسة.

\section{تطبيق الدراسة:}

بعد تحديد مشكلة الدراسة، وأسئلتها ومتغيراتا، وبعد الانتهاء من إعداد أداة الدراسة، والتأكد من صدقها وثباها، طبقت على عينة الدراسة في الفصل الدراسي الأول (2022/2021) عن طريق توزيع الرابط في البريد الإلكتروني وبواسطة برنامج "الواتس اب" لعينة الدراسة.

\section{المعالجة الإحصائية:}

لتحقيق أهداف الدراسة استخدم الباحثان برنامج الرزمة الإحصائية (SPSS) في تحليل البيانات التي تم جمعها بعد تطبيق أداة الدراسة وهي: وهي: معامل الثبات ألفاكرونباخ، والمتوسطات الحسابية والانحرافات المعيارية والأهمية النسبية (الرتبية)، وتحليل التباين الأحادي، الموضح في الجدول (2) لتفسير تقديرات أفراد العينة. جدول (2) المعيار الإحصائي لتفسير تقديرات أفراد العينة

\begin{tabular}{|c|c|c|}
\hline درجة المعوقات/ التحديات & مدى الدرجات & الدرجة \\
\hline كبيرة جدا & $4.20-5.00$ & 5 \\
\hline كبيرة & $3.40-4.19$ & 4 \\
\hline متوسطة & $2.60-3.39$ & 3 \\
\hline قليلة & $1.80-2.59$ & 2 \\
\hline قليلة جداً & $0-1.79$ & 1 \\
\hline
\end{tabular}




\section{نتائج الدراسة ومناقشتها}

\section{نتائج السؤال الأول ومناقشتها:}

للإجابة عن هذا السؤال ونصه: ما درجة المعوقات التي يواجهها معلمو العلوم والرياضيات في توظيف مهارات المستقبل

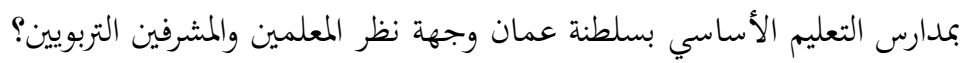

تم استخراج المتوسطات الحسابية والانخرافات المعيارية لجميع بجالات أداة الاستبانة والمجال العام حيث تم ترتيبها ترتيبا

تنازلياً كما هو واضح في الجدول (3)

جدول (3) المتوسطات الحسابية والانخرافات المعيارية لمجالات الاستبانة والمتوسط العام للدراسة

\begin{tabular}{|c|c|c|c|c|}
\hline التحدي & المعياري الانراف & المستوسطي & 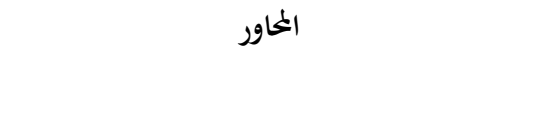 & s \\
\hline كبيرة & 0.73 & 3.81 & المعوقات التي تتعلق بالمعلم. & 1 \\
\hline كبيرة & 0.72 & 3.80 & المعوقات المتعلقة بالمتعلم. & 2 \\
\hline كبيرة & 0.62 & 3.60 & المعوقات المتعلقة بطرائق تدريس مهارات المستقبل. & 3 \\
\hline كبيرة & 0.75 & 3.53 & المعوقات المتعلقة بقياس مهارات المستقبل وتقويكها. & 4 \\
\hline متوسطة & 0.63 & 3.39 & المعوقات المتعلقة بمنهج الرياضيات والعلوم. & 5 \\
\hline كبيرة & 0.62 & 3.64 & المتوسط العام & \\
\hline
\end{tabular}

يتضح من الجدول (3) أنه على المستوى العام فإن درجة المعوقات التي يواجهها معلمو العلوم والرياضيات في توظيف

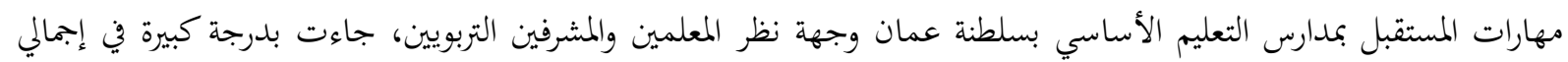

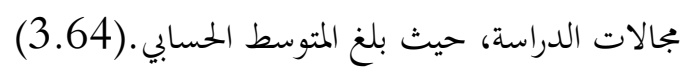

وقد تراوحت المتوسطات الحسابية لكل مجال من مجالات أداة الدراسة بين (3.81-3.39) بين الكبيرة والمتوسطة، حيث جاء بجال "المعوقات المتعلقة بالمعلم" في المرتبة الأولى بمتوسط حسابي (3.81) بدرجة كبيرة، في حين جاء مباء مجال "المعوقات المتعلقة بالمتعلم" في المرتبة الثانية بمتوسط حسابي (3.80) بدرجة كبيرة. وجاء في المرتبة الثالثة مجال " المعوقات المتعلقة بطرائق

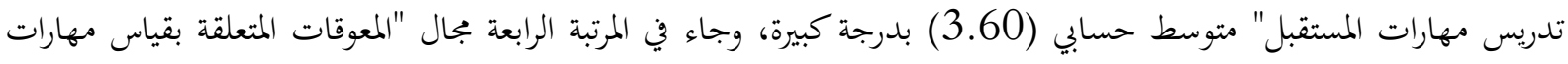
المستقبل وتقويمها" بمتوسط حسابي (3.53) بدرجة كبيرة، في حين جاء في المرتبة الأخير بجال " المعوقات المتعلقة بمنهج الرياضيات والعلوم" بمتوسط حسابي (3.39) بدرجة متوسطة. ويمكن أن تعزى هذه النتيجة إلى كثرة الأعمال الإدارية والفنية التي

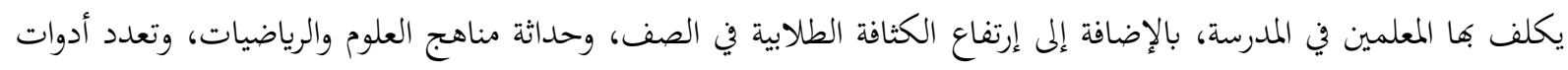
التقويم وتقنياته في ضوء المناهج المطورة، كما يعود ذلك على قلة البرامج التدريبية، وصعوبة المناهج التي تطبق لأول مره في المدارس

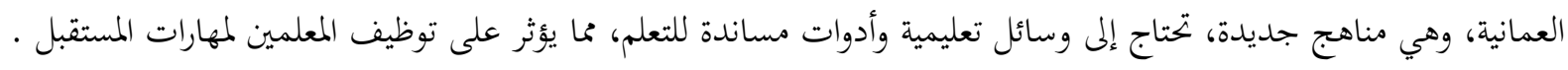
أما عما أظهرته نتائج الدراسة حول كل مجال من مجالات الدراسة فقد جاءت المتوسطات الحسابية والاخرافات المعيارية

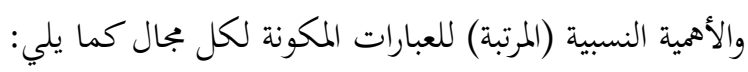

\section{البجال الأول: المعوقات المتعلقة بمنهج الرياضيات والعلوم}

المتوسطات الحسابية والانحرافات المعيارية والأهمية النسبية (المرتبة) للعبارات المكونة للمجال الأول المعوقات المتعلقة بمنهج

الرياضيات والعلوم، ويوضح ذلك الجدول (4) 
جدول (4) المتوسطات الحسابية والانرافات المعيارية لمجال المعوقات المتعلقة بمنهج الرياضيات والعلوم

\begin{tabular}{|c|c|c|c|c|}
\hline 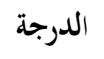 & الانخراف المعياري & المتوسط الحسابي & 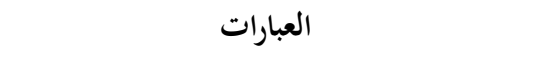 & b \\
\hline كبيرة & 1.04 & 3.58 & ضعف مراعاة المنهج لحاجات المتعلمين وميولم. & 1 \\
\hline كبيرة & 1.09 & 3.47 & ضعف استخدام المنهج للتكنولوجيا التعليمية. & 2 \\
\hline كبيرة & 1.07 & 3.45 & افتهارات المنهج للأنشطة التي تساعد على تطبيق & 3 \\
\hline كبيرة & 1.01 & 3.38 & والمشكلات ارتباط الجانب المعريف بالتطبيقات & 4 \\
\hline كبيرة & 1.10 & 3.38 & عدم مناسبة الأهداف والمحتوى لمهارات المستقبل. & 5 \\
\hline كبيرة & 1.13 & 3.37 & لا لا يهتم المنهج بتدريس المحتوى الذي يساعد على & 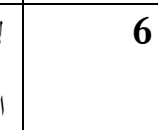 \\
\hline كبيرة & 0.98 & 3.36 & ضعفف تضمين المنهج للمفاهيم التي تشكلت لدى & 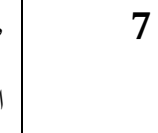 \\
\hline متوسطة & 1.10 & 3.16 & لا يقدم المنهج فرص للمتعلم للتعلم الذاتي. & 8 \\
\hline كبيرة & 0.83 & 3.39 & & المتوسط العام \\
\hline
\end{tabular}

يتضح من الجدول (4) بأنه على المستوى العام فإن درجة المعوقات التي يواجهها معلمو العلوم والرياضيات في توظيف مهارات المستقبل بمدارس التعليم الأساسي بسلطنة عمان وجهة نظر المعلمين والمشرفين التربويين في بجال المعوقات المتعلقة بمنهج الرياضيات والعلوم جاءت بدرجة كبيرة حيث بلغ المتوسط الحسابي (3.39) واحتل بذلك المرتبة الخامسة بالنسبة لمجالات الدراسة

أما المتوسطات الحسابية لكل عبارة من عبارات المجال فقد تراوحت بين (3.58-3.16) بين الكبيرة والمتوسطة، وكانت الأكثر معوقاً عبارة "ضعف مراعاة المنهج لحاجات المتعلمين وميولم" بمتوسط حسابي (3.58) وبدرجة كبيرة. في حين كانت

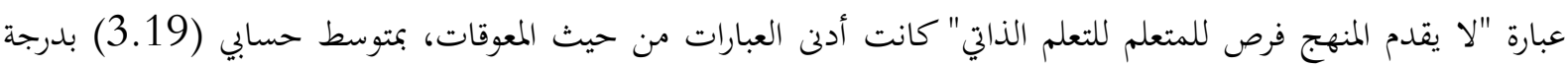

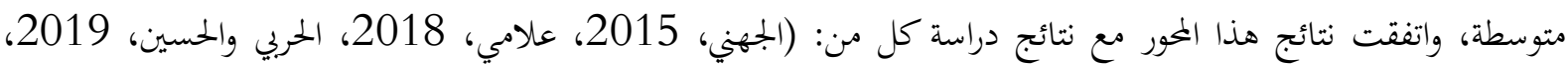
عليان والمزروعي، 2020).

وتعزى هذه النتيجة إلى حداثة المناهج وبعض الأخطاء التي تحتويها، وتعدد محاور وبجالات محتوى المناهج، وزيادة عدد الوحدات الدراسية المضمنة في المنهج حيث بلغت في بعض المراحل إلى ضعف عدد الوحدات التي تضمنتها المناهج السابقة. 


\section{المجال الثاين: المعوقات المتعلقة بطرائق تدريس مهارات المستقبل}

المتوسطات الحسابية والانحرافات المعيارية والأهمية النسبية (المرتبة) للعبارات المكونة للمجال الثاني المتعلقة بطرائق تدريس

$$
\text { مهارات المستقبل، ويوضح ذلك الجدول (5) . }
$$

جدول (5) المتوسطات الحسابية والاخرافات المعيارية لمجال المعوقات المتعلقة بطرائق تدريس مهارات المستقبل.

\begin{tabular}{|c|c|c|c|c|}
\hline الدرجة & الانحراف المعياري & المتوسط المتي & العبارات & b \\
\hline كبيرة & 1.07 & 4.13 & 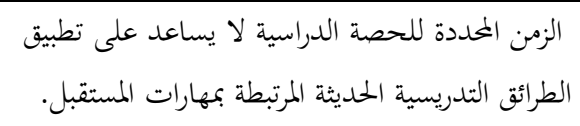 & 1 \\
\hline كبيرة & 0.97 & 4.05 & 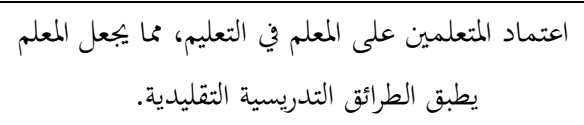 & 2 \\
\hline كبيرة & 0.99 & 3.90 & ضعف البيئة التقنية لتوظيف استراتيجيات التعليم & 3 \\
\hline كبيرة & 1.10 & 3.54 & 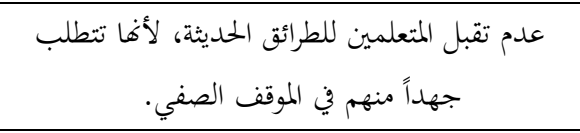 & 4 \\
\hline كبيرة & 0.96 & 3.37 & لا تساعد على توظيف المهارات في المواقف التعليمية & 5 \\
\hline كبيرة & 1.07 & 3.33 & عدم إلمام المعلم بالاستراتيجيات التدريسية الحديثة & 6 \\
\hline كبيرة & 1.06 & 3.30 & 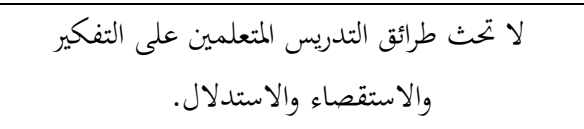 & 7 \\
\hline كبيرة & 1.07 & 3.23 & الطرائق التدريسية لا تساعد على تنمية مهارات & 8 \\
\hline كبيزة & 0.75 & 3.60 & المتوسط العام & \\
\hline
\end{tabular}

يتضح من الجدول (5) بأنه على المستوى العام فإن درجة المعوقات التي يواجهها معلمو العلوم والرياضيات في توظيف مهارات المستقبل بمدارس التعليم الأساسي بسلطنة عمان وجهة نظر المعلمين والمشرفين التربويين في مجال المعوقات المتعلقة بطرائق تدريس مهارات المستقبل، جاءت بدرجة كبيرة حيث بلغ المتوسط الحسابي (3.60) واحتل بذلك المرتبة الثالثة بالنسبة لمجالات الدراسة الخمسة.

أما المتوسطات الحسابية لكل عبارة من عبارات المجال فقد تراوحت بين (4.13-3.23) بدرجة الكبيرة، وكانت الأكثر

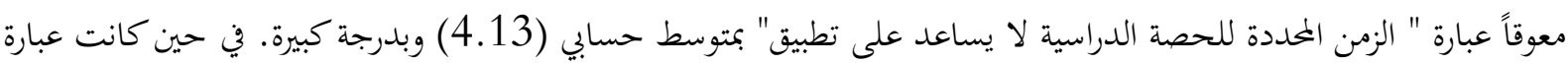

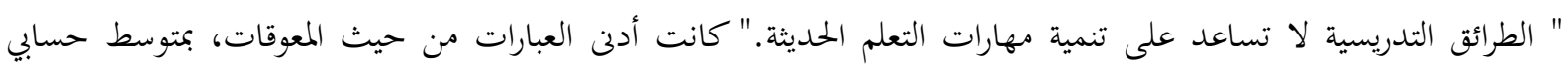

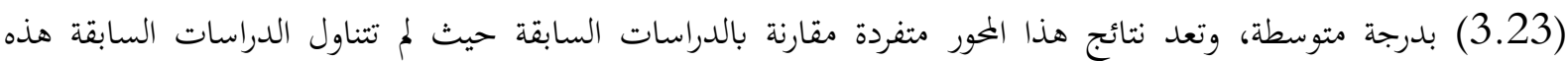
المعوقات في حدود علم الباحثين.

وتعزى هذه النتيجة إلى عدم تمكين المعلمين من تعلم الاستراتيجيات الحديثة، وعدم وضوحها في المنهج حيث جاءت

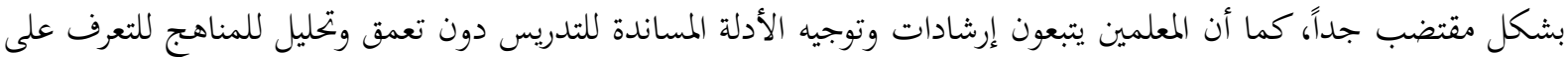
تلك الاستراتيجيات والطرائق المدبجة في كتاب الطالب. 
المجال الثالث: المعوقات التي تتعلق بالمعلم.

المتوسطات الحسابية والانرافات المعيارية والأهية النسبية (المرتبة) للعبارات المكونة للمجال الثالث المعوقات المتعلقة

$$
\text { بالمعلم، ويوضح ذلك الجدول.(6) }
$$

جدول (6)المتوسطات الحسابية والانخرافات المعيارية لمجال المعوقات المتعلقة بالمعلم

\begin{tabular}{|c|c|c|c|c|}
\hline 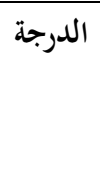 & المعياري & المسابي & 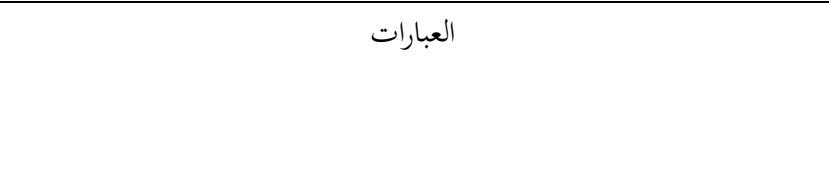 & s \\
\hline كبيرة & 0.85 & 4.42 & كثرة الأعباء الإدارية التي يقوم .ما المعلم. & 1 \\
\hline كبيرة & 1.02 & 4.10 & لا يتيح وقت الحصة فرص للحوار الاجتماعي بين المتعلمين. & 2 \\
\hline كبيرة & 1.04 & 3.90 & صعوبة توجيه الدرس في ضوء تفكير المتعلمين وخبراقم السابقة لأن هذا يمتاج & 3 \\
\hline كبيرة & 1.04 & 3.90 & قلة البرامج التدرييية المتعلقة برفع كفاءة المعلم. & 4 \\
\hline كبيرة & 1.00 & 3.54 & صعوبة استخدام الطرائق التدريسية التي تركز على نشاط المتعلم. & 5 \\
\hline كبيرة & 1.03 & 3.48 & صعوبة توجيه المتعلمين على اكتساب المعرفة نتيجة لتفاعلهم مع العالم الخارجي. & 6 \\
\hline كبيرة & 1.06 & 3.35 & عدم الاقتناع بأهمية توظيف مهارات المستقبل في الموقف الصفي & 7 \\
\hline كبيرة & 0.73 & 3.81 & المتوسط العام & \\
\hline
\end{tabular}

يتضح من الجدول (6) بأنه على المستوى العام فإن درجة المعوقات التي يواجهها معلمو العلوم والرياضيات في توظيف

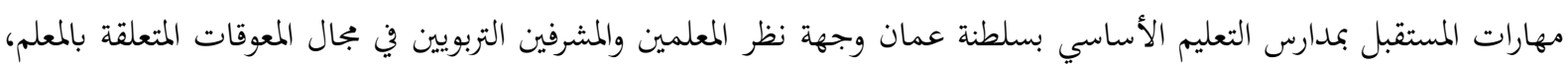

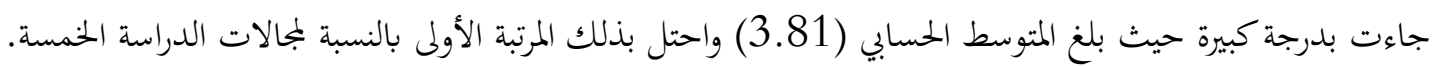

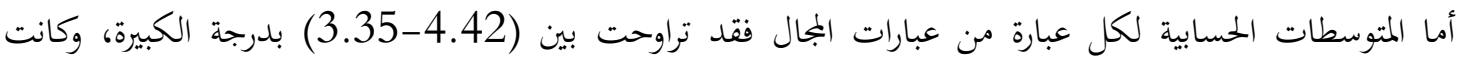

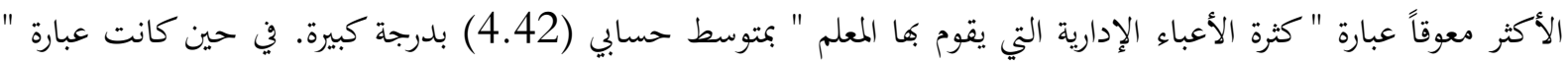

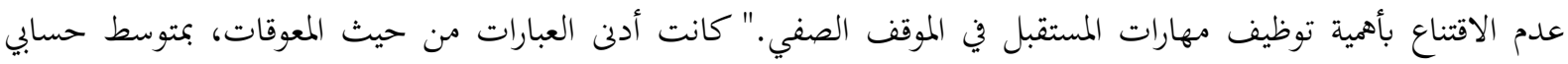
(3.35) بدرجة كبيرة، وجاءت نتائج هذا المحور متفقة مع دراسة كل من: (الجهني، 2015، علامي، 2018). وتعزى هذه النتيجة إلى تعدد المناهج التي يدرسها المعلمون في بعض المدارس، وإرتفاع أنصبتهم، وتغيب البعض منهم

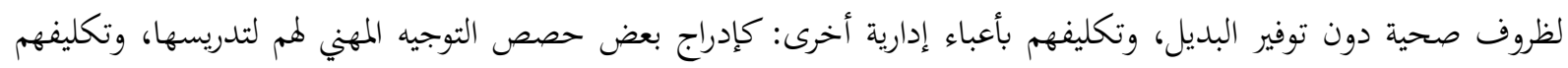
بأنشطة المدرسة مثل الجدول المدرسي. الجمال الرابع: المعوقات المتعلقة بالمتعلم. المتوسطات الحسابية والانحرافات المعيارية والأهمية النسبية (المرتبة) للعبارات المكونة للمجال الثاني المتعلقة بالمتعلم، ويوضح ذلك الجدول.)(7) جدول (7) المتوسطات الحسابية والانخرافات المعيارية لمجال المعوقات المتعلقة بالمتعلم

\begin{tabular}{|c|c|c|c|c|}
\hline الدرجة & الانمراف & المتوسط & 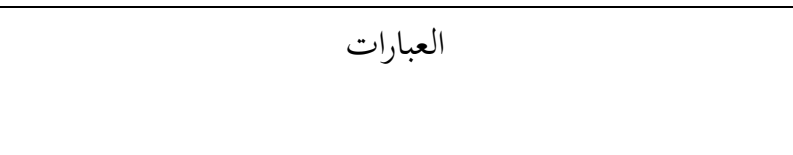 & م \\
\hline 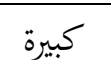 & 0.91 & 4.37 & إرتفاع كثافة المتعلمين في الصف. & 1 \\
\hline 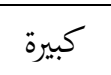 & 0.92 & 4.16 & اعتماد المتعلمين الضعاف على زملائهم المتفوقين في المجموعات. & 2 \\
\hline
\end{tabular}




\begin{tabular}{|c|c|c|c|c|}
\hline 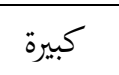 & 0.99 & 4.01 & ضعف مهارات القراءة والكتابة لدى المتعلمين. & 3 \\
\hline كبيرة & 0.95 & 3.86 & عدم قيام المتعلمين بإنجاز المهام المكلفين بها. & 4 \\
\hline كبيرة & 1.07 & 3.75 & لا يسمح وقت الحصة بتعبير المتعلم عن رأيه. & 5 \\
\hline 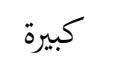 & 0.93 & 3.69 & ضعف الثقة بالنفس لدى بعض المتعلمين. & 6 \\
\hline كبيرة & 1.06 & 3.43 & عدم تقبل المتعلمين للأنشطة التي تتطلب مشاركتهم في الموقف & 7 \\
\hline 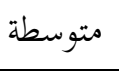 & 1.22 & 3.17 & تكرار غياب المتعلمين بصورة مستمرة طوال العام الدراسي. & 8 \\
\hline كبيرة & 0.75 & 3.60 & المتوسط العام & \\
\hline
\end{tabular}

يتضح من الجدول (7) بأنه على المستوى العام فإن درجة المعوقات التي يواجهها معلمو العلوم والرياضيات في توظيف مهارات المستقبل بمدارس التعليم الأساسي بسلطنة عمان من وجهة نظر المعلمين والمشرفين التربويين في مجال المعوقات المتعلقة بالمتعلم جاءت بدرجة كبيرة حيث بلغ المتوسط الحسابي (3.69) واحتل بذلك المرتبة الثانية بالنسبة لمجالات الدراسة الخمسة فئسة أما المتوسطات الحسابية لكل عبارة من عبارات المجال فقد تراوحت بين (4.37-3.17) بدرجة كبيرة، وكانت الأكثر معوقاً عبارة " إرتفاع كثافة المتعلمين في الصف" بمتوسط حسابي (4.37) وبدرجة كبيرة. في حين كانت عبارة تكرار غياب

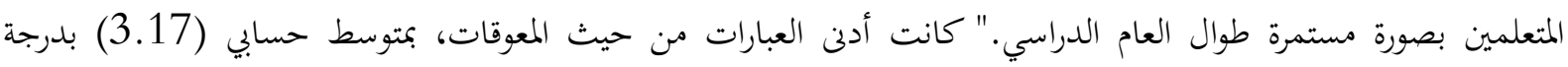
متوسطة، واتفقت نتائج هذا المحور مع دراسات كل من: (الجهني، 2015، عليان والمزروعي، 2020). وتعزى هذه النيجة إلى ضعف الدافعية لدى المتعلمين، وتصوراتم المسبقة حول صعوبة تعلم العلوم والرياضيات، وقلة

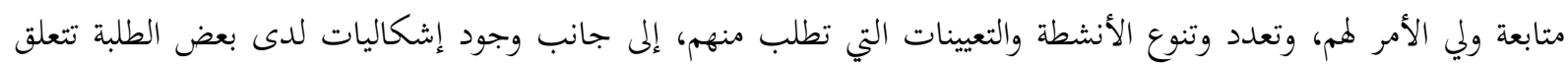
بمهارات القراءة والكتابة.

\section{الجمال الخامس: المعوقات المثعلقة بقياس مهارات المستقبل وتقويمها.}

المتوسطات الحسابية والانحرافات المعيارية والأهمية النسبية (المرتبة) للعبارات المكونة للمجال الخامس المعوقات المتعلقة

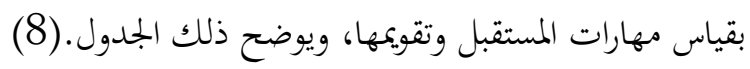
جدول (8) المتوسطات الحسابية والاخرافات المعيارية لمجال المعوقات المتعلقة بقياس مهارات المستقبل ونعبل وتقويمها

\begin{tabular}{|c|c|c|c|c|}
\hline 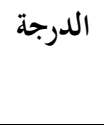 & اللمعياري & المستوسطي & 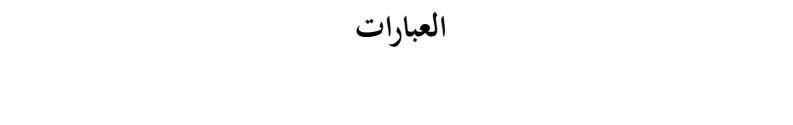 & b \\
\hline كبيرة & 0.88 & 4.04 & تعتمد أساليب التقويم على الكتابة بصورة كبيرة. & 1 \\
\hline كبيرة & 0.81 & 3.65 & يرتبط نظام التقييم للمعايير بلمنهج الدراسي والانماء المهني للكوادر التدرييية & 2 \\
\hline كبيرة & 0.94 & 3.63 & لا تشجع أدوات التقويم المتعلمين على قياس مهارات المستقبل لدى الطلبة. & 3 \\
\hline كبيرة & 0.84 & 3.55 & تركز المؤشرات على قياس مهارات التفكير العليا & 4 \\
\hline كبيرة & 0.92 & 3.53 & عدم إعطاء المتعلمين الفرصة للتقويم الذاتي وتقويم الأقران. & 5 \\
\hline 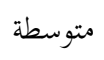 & 1.00 & 3.32 & ضعف العلاقة بين أساليب التقويم والأهداف التعليمية. & 6 \\
\hline 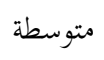 & 0.92 & 3.30 & يستخدم التقويم الالكتروني وبرجياته لمتابعة مدى تطبيق المهارات وتقييمها & 7 \\
\hline 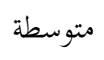 & 0.94 & 3.29 & لا تراعي الأسئلة الفروق الفردية بين المتعلمين. & 8 \\
\hline كبيرة & 0.63 & 3.53 & المتوسط العام & \\
\hline
\end{tabular}


يتضح من الجدول (8) بأنه على المستوى العام فإن درجة المعوقات التي يواجهها معلمو العلوم والرياضيات في توظيف

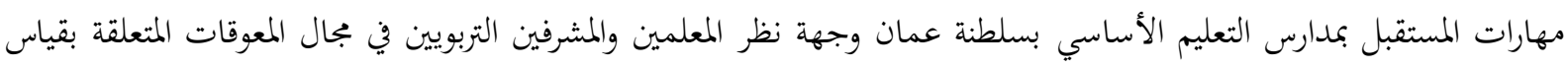
مهارات المستقبل وتقويمها جاءت بدرجة كبيرة حيث بلغ المتوسط الحسابي (3.69) واحتل بذلك المرتبة الرابعة بالنسبة لمجالات

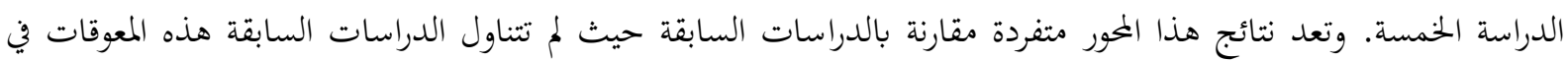
حدود علم الباحثين.

أما المتوسطات الحسابية لكل عبارة من عبارات المجال فقد تراوحت بين (4.04-3.29) بدرجة الكبيرة، وكانت الأكثر

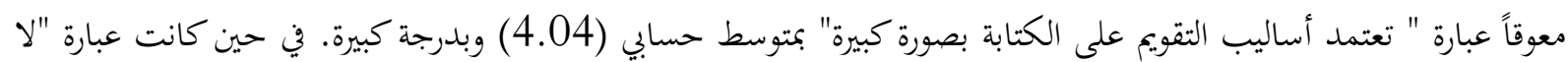
تراعي الأسئلة الفروق الفردية بين المتعلمين" كانت أدنى العبارات من حيث المعوقات، بمتوسط حسابي (3.29) بدرجة متوسطة. وتعزى هذه النتيجة إلى تعدد تقنيات التقويم وأدواته وعدم تمكن المعلمين من ممارستها في المواقف الصفية، وضعف

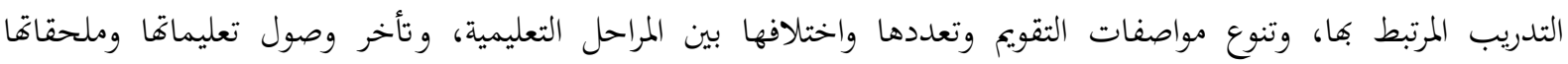
كلمعين.

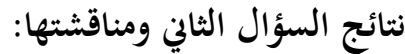

للإجابة عن السؤال الثاني الذي نصه: هل توجد فروق ذات دلالة إحصائية في درجة المعوقات يواجهها معلمو العلوم

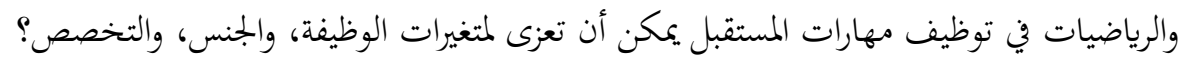

أ) الوظيفة للكشف عن أثر متغير الوظيفة تم استخدام المتوسطات الحسابية والاخرافات المعيارية واختبار (T-Test)، ويوضح ذلك

الجدول (9).

جدول (9) المتوسطات الحسابية والانحرافات المعيارية واختبار(T-Test) تبعاً لمتغير الوظيفة

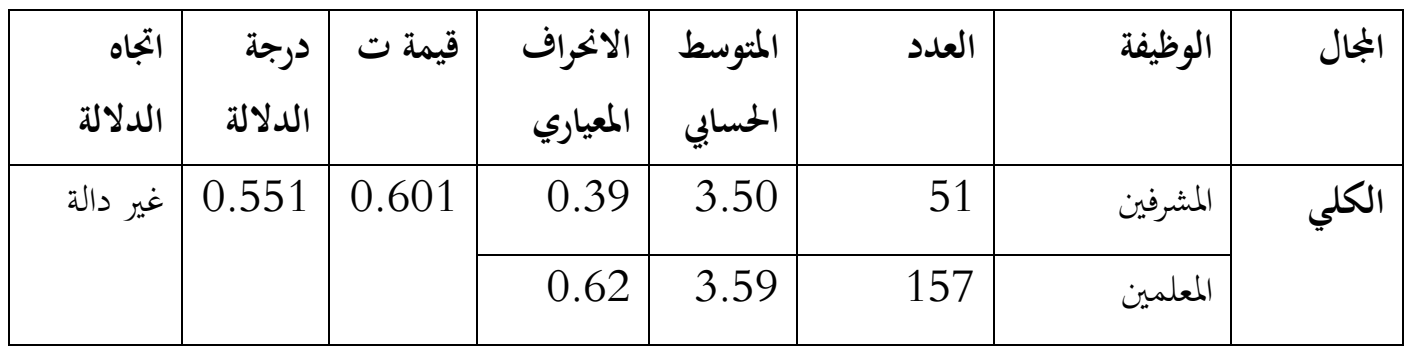

تشير نتائج الجدول (9) إلى عدم وجود فروق ذات دلالة إحصائية عند درجة الدلالة (م=0.05)في درجة المعوقات التي يواجهها معلمو العلوم والرياضيات في توظيف مهارات المستقبل يمكن أن تعزى إلى متغير الوظيفة. واتفقت نتائج هذا السؤال مع نتيجة دراسة (علامي، 2018). ويمكن تفسير هذه النتيجة بأن كل من المشرف والمعلم يشتركون في كثير من المهام المرتبطة

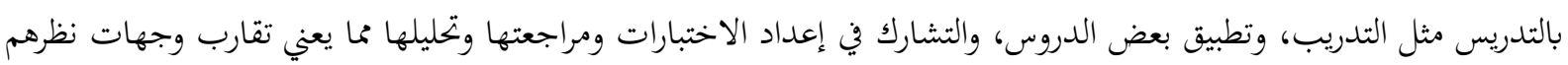
حول كثير من موضوعات التدريس.

للإجابة عن هذا السؤال (متغير التخصص) تم استخدام المتوسطات الحسابية والانخرافات المعيارية واختبار(T-Test)، ويوضح الجدول (10) ذلك. 
جدول (10) المتوسطات الحسابية والانخرافات المعيارية واختبار( T-Test) تبعاً لمتغير التخصص

\begin{tabular}{|c|c|c|c|c|c|c|c|}
\hline الداه & درجة & قيمة ت & الالمعياري & المتوسط المسابي & العدد & الوظيفية & الججال \\
\hline \multirow[t]{2}{*}{ دالة } & \multirow[t]{2}{*}{0.005} & \multirow[t]{2}{*}{2.842} & 0.59 & 3.73 & 139 & الرياضيات & \multirow[t]{2}{*}{ التخصص } \\
\hline & & & 0.64 & 3.47 & 69 & العلوم & \\
\hline
\end{tabular}

تشير نتائج الجدول (10) إلى وجود فروق ذات دلالة إحصائية عند درجة الدلالة (0.05=0)بين درجة المعوقات التي يواجهها معلمو العلوم والرياضيات في توظيف مهارات المستقبل تعزى إلى التخصص ولصالح مادة الرياضيات، وتتفق هذه النتيجة مع ما توصلت إليه دراسة الحربي والحسين(2019). ويعزى ذلك إلى عدة عوامل منها طول منهج الرياضيات مقارنة بالعلوم، وكذلك العبء التدريسي، والتطوير المستمر للمناهج، والتعيينات الجديدة في الرياضيات.

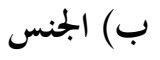

للإجابة عن هذا السؤال (متغير الجنس) تم استخدام المتوسطات الحسابية والانخرافات المعيارية واختبار (T-Test)، ويوضح الجدول (11) ذلك. جدول (11) المتوسطات الحسابية والانحرافات المعيارية واختبار(T-Test) تبعاً لمتغير الجنس

\begin{tabular}{|c|c|c|c|c|c|c|c|}
\hline الدالة الداه & الدلالة & قيمة ت & الالمعراف & المتوسط & العدد & الجنس & البجال \\
\hline \multirow[t]{2}{*}{ غير دالة } & \multirow[t]{2}{*}{0.087} & \multirow[t]{2}{*}{1.719} & 0.59 & 3.71 & 114 & ذكور & \multirow[t]{2}{*}{ لكلي } \\
\hline & & & 0.64 & 3.56 & 94 & إناث & \\
\hline
\end{tabular}

تشير نتائج الجدول (11) إلى عدم وجود فروق ذات دلالة إحصائية عند درجة الدلالة (0.05=0 ه) بين درجة المعوقات يواجهها معلمو العلوم والرياضيات في توظيف مهارات المستقبل، وتختلف هذه النتيجة مع ما توصلت إليه دراسة الحربي والحسين

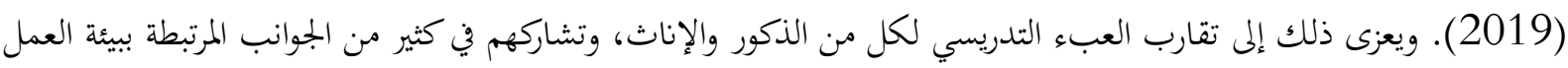
كالتحضير والتدريب من خلال مجتمعات التعلم المهنية المشتركة.

\section{توصيات الدراسة}

في ضوء النتائج التي توصلت إليها الدراسة، يوصي الباحثان بالآتي: 1. تخفيف الأعباء الإدارية عن المعلمين.

2. حث المعلمين على تطبيق الاستراتيجيات التدريسية الحديثة، والأنشطة التقويمية التي تركز على مهارات المستقبل.

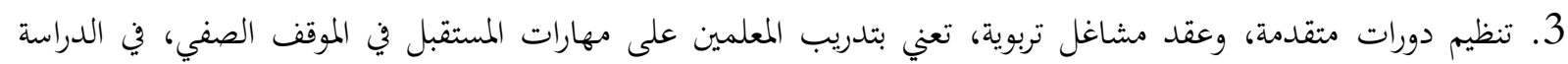
الجامعية، وأثناء الخدمة. 


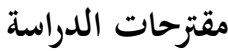

يوصي الباحثان إجراء مجموعة من الدراسات المرتبطة بموضوع الدراسة الحالية، وهي كالآتي: 1. دراسة الاحتياجات التدريبة اللازمة لتوظيف مهارات المستقبل في التدريس من قبل معلمي العلوم والرياضيات بالحلقة الثانية من التعليم الأساسي.

2. دراسة أثر البرامج التدريبية أثناء الخدمة في توظيف معلمو العلوم والرياضيات لمهارات المستقبل على المستوى التحصيلي للطلبة . 


\section{المراجع}

أبوعابد، محمد. (2005). المرجع في الإشراف التربوي والعملية الإشرافية. دار الكتاب الثقافي.

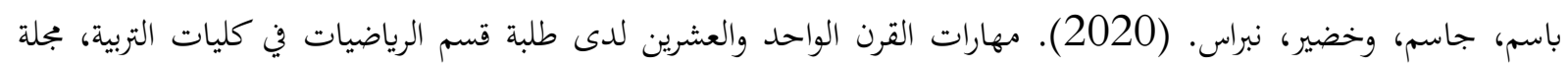

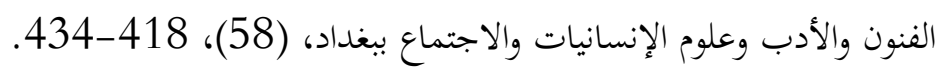

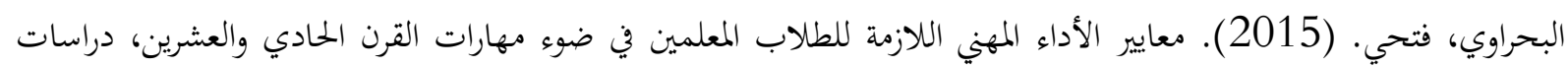

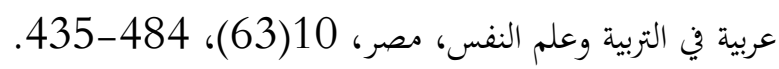

البلوشي، جليلة، والمعمري، سيف. (2021). مهارات المستقبل: دليل لمؤسسات التعليم وقطاع سوق العمل. سلطنة عمان.

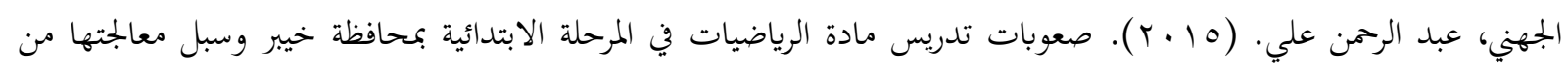
وجهة نظر معلميها، (رسالة ماجستير غير منشورة). الجامعة الإسلامية، المدينة المنورة.

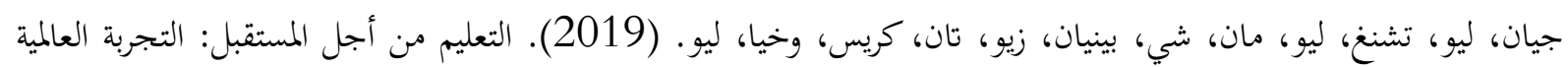

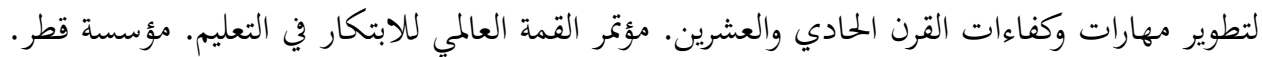
الحسين، أحمد، والحربي، حصة. (2019). معوقات تنفيذ الأنشطة التعليمية في مقررات العلوم للصفوف العليا من المراحل الابتدائية من وجهة نظر المعلمات والمشرفات. رسالة التربية وعلم النفس. (53) (257-285.

الدرمكي، عائشة. (28أغسطس 2021). مهارات المستقبل العاجلة. مقالة بجريدة عمان اليوم مسترجعة بتاريخ https://www.omandaily.om/2021/11/27 دويكات، لؤي نمر. (7 ا • Y). مدى فهم معلمي المرحلة الأساسية الدنيا للمفاهيم الرياضية في محافظة نابلس (رسالة ماجستير غير منشورة). جامعة النجاح الوطنية في نابلس، فلسطين. زيتون. عايش محمود. (2013). أساليب تدريس العلوم. دار الشروق للنشر والتوزيع. شلبي، نوال. (2014). إطار مقترح لدمج مهارات القرن الحادي والعشرين في مناهج العلوم بالتعليم الأساسي في مصرد الثروف المجلة

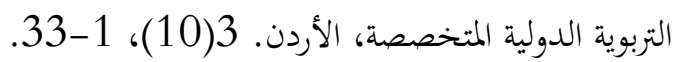

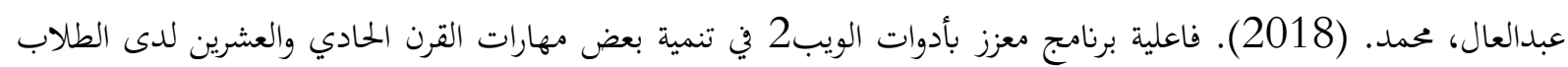

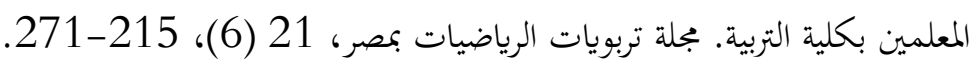

العقالي، محمد أحمد. (2018). معوقات توظيف تكنولوجيا الواقع الافتراضي في تدريس الرياضيات من وجهة نظر المعلمات في ترئي

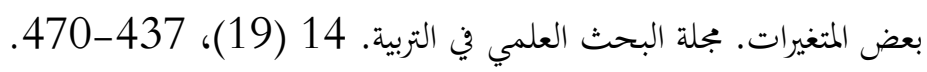

علامي، علي بن حمد. (2018). معوقات تدريس المفاهيم الرياضية من وجهة نظر معلمي ومشريز الرياضيات في محافظة صبيا. مجلة كلية التربية. (18)، 217-248.

عليان، شاهر، والمزروعي، يوسف. (2020). معوقات تطبيق منحى STEM في تدريس العلوم من جهة نظر المعلمين في

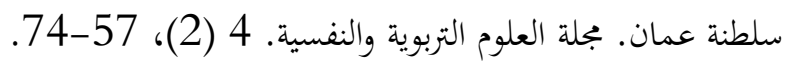

الفياض، راشد (2009). تطوير مناهج العلوم في ضوء الاتحاهات العالمية الحميثة (رؤية مستقبلية). دار عالم الكتب. مجلس التعليم. (2021). الإطار الوطني العُماني لمهارات المستقبل. سلطنة عمان. محمد، أسماء السيد، ومحمد، كريمة محمود. (2020). تطبيقات الذكاء الاصطناعي ومستقبل تكنولوجيا التعليم. المجموعة العربية للتدريب والنشر.

مؤسسة محمد بن راشد آل مكتوم للمعرفة، المكتب الإقليمي للدول العربية. (د.ت). استشراف مستقبل المعرفة. الغرير للطباعة والنشر 
Melhem, Tareq (2020). level of 21st century skills among students of the Special Education Department in the College of Education at King Faisal University, Journal of Scientific Research in Education. King Faisal University (Saudi Arabia) College of Education, 21(3), 272-303.

The Economist Intelligence Unit (2017). Worldwide Educating for the Future Index: A benchmark for the skills of tomorrow. Available from: https://dkf1ato8y5dsg.cloudfront.net/uploads/5/80/eiu-yidan-prize-educating-forthe-future-wp-fi nal.pdf 